\title{
ASSESSMENT OF THE OUTCOME OF LOW BACK SURGERY
}

\author{
GORDON WADDELL, STUART REILLY, BEN TORSNEY, DAVID B. ALLAN, EMYR W. MORRIS, \\ MICHAEL P. DI PAOLA, MARTIN BIRCHER, DAVID FINLAYSON
}

From Western Infirmary, Glasgow and the University of Glasgow

\begin{abstract}
We aimed to develop a better understanding and method of rating the success or failure of low back surgery by studying 185 patients prospectively. Identical pre-operative and postoperative assessment by an independent observer included pain, disability, physical impairment, psychological distress and illness behaviour. Outcome was assessed by the patient, by the observer and by return to work. There was $96 \%$ follow-up at two years.

Correlation co-efficients varied considerably between the various measures of outcome, both patient and observer appearing to base their assessment mainly on postoperative status rather than on any change produced by surgery. The observer was influenced most by postoperative pain, disability and physical impairment. Patients were influenced most by residual physical impairment, type of surgery and proportional change in disability. Return to work was moderately influenced by postoperative disability and to a larger extent by social and work-related factors.

We developed a simple formula to judge overall success or failure which accurately reproduced the combined assessment of patient and observer. If surgical audit is to be meaningful it must be based on an improved understanding of how the outcome of surgery should be assessed.
\end{abstract}

Although it is now routine practice, the actual process of assessing the outcome of any form of surgery is poorly understood. This is particularly obvious in low back surgery.

The wide variation in reported success rates of operations on the low back has been variously attributed to patient selection, surgical technique or simply to the method of assessing the outcome. Previous workers have used assessment by the patient, the surgeon or an independent observer, or by measures of function such as return to work. These have been used either singly or in combination (Howe and Frymoyer 1985; Weinstein et al. 1986). It has been observed that there are discrepancies between these different measures of outcome; individual patients or series of patients may be rated differently by

G. Waddell, BSc, MD, FRCS, Consultant Orthopaedic Surgeon D. B. Allan, FRCS, Senior Orthopaedic Registrar

E. W. Morris, FRCS, Spinal Research Fellow

M. P. Di Paola, FRCS, Spinal Research Fellow

M. Bircher, FRCS, Spinal Research Fellow

D. Finlayson, FRCS, Spinal Research Fellow

Orthopaedic Department, Western Infirmary, Glasgow G11 6NT, Scotland.

S. Reilly, BSc, Honours Student in Statistics

B. Torsney, MSc, PhD, Lecturer in Statistics

Department of Statistics, University of Glasgow, Glasgow G12 8QQ, Scotland.

Correspondence should be sent to Mr G. Waddell.

(C) 1988 British Editorial Society of Bone and Joint Surgery

0301-620X/88/5182 \$2.00

J Bone Joint Surg [Br] 1988;70-B:723-7. each method. Attempts to combine these assessments have been empirical and have not gained general acceptance. Moreover, it is not clear how either the patient or the surgeon arrive at their assessment or which factors affect return to work.

In previous studies we have identified the main clinical elements of low back disorders as pain, disability and physical impairment, psychological distress and illness behaviour (Waddell and Main 1984; Waddell et al. 1984). Our present study aims to analyse the relationship between the various methods of assessing outcome and to identify which clinical elements influenced each assessment. We hope that this will clarify the assessment and permit the development of a simple but more rational system of rating surgical results.

\section{MATERIAL AND METHODS}

We made a prospective study of white, native-born British patients before and after various types of surgery for low back pain and sciatica (Table I). Of 185 patients with complete follow-up, 49 had chemonucleolysis, 91 had first operations for disc prolapse, 20 had spine fusion for low back pain and 25 had repeat operations on the spine. Patients were aged from 20 to 60 years and we excluded all those with spinal pathology such as tumour or infection, a history of psychiatric disorder or alcohol abuse, or inability to read or write. We have reported details of these patients previously (Waddell et al. 1986). 
All patients had a standard assessment by an independent observer from one to five days before operation, and both pre-operative and postoperative assessment included a detailed clinical history and physical examination with measurement of pain scale, functional disability, and of objective physical impairment (Waddell 1987). Psychological distress was assessed by the modified somatic perception questionnaire (MSPQ, Main 1983) and the Zung depression scale (Zung 1965). Clinical assessment of illness behaviour was based on a pain drawing (Ransford, Cairns and Mooney 1976), the detection of behavioural symptoms (Waddell et al. 1984), and behavioural signs (Waddell et al. 1980).

At follow-up the outcome was assessed independently by the patient, by the observer and from the work record. The patient's assessment was obtained by asking "in speaking to me as an unbiased third party, do you honestly feel that the operation was worthwhile and would you go through with it again?" It was emphasised that the observer was not involved in any way with the surgery or present medical care. The patient decided on the basis of this question whether the operation had been worthwhile, doubtful or not worthwhile.

The observer's assessment was based on the standard, commonly used rating of good, fair or poor (Spangfort 1972). A good result was defined as virtually no pain and no alteration in lifestyle. A fair result was scored for occasional pain relieved by short periods of bed rest or analgesics and requiring only minor alterations in activities including employment. A poor result was frequent or disabling episodes of low back pain or sciatica with need for long-term narcotics, further surgery or inability to work. The work record was analysed for return to work, type of employment and duration of sick certification both before and after operation. The follow-up rate was $96 \%$.

Statistical analysis. All information was stored on an ICL 2988 computer with a comprehensive SPSS control file. The data could be divided into a number of categorical and continuous variables and a series of statistical methods were used in the analysis. In essence, these measured the relationship between the different assessments of outcome and also identified those factors which most influenced each assessment. Initial studies included Pearson's product moment correlation co-efficients, analysis of variance, logistic regression and various tests on contingency tables. The final analysis was based on further logistic regression analysis using the BMDP PLR stepwise regression programme (Reilly 1987).

\section{RESULTS}

The results are presented in four stages. First, the basic data is given and the relationship analysed between the patient's assessment, the observer's assessment and return to work. The second section analyses whether the patient's assessment, the observer's assessment and return to work are influenced mainly by the preoperative state, the postoperative state or the degree of change resulting from the operation. The third section continues this statistical analysis to identify which particular elements of the illness or surgery influence the patient's assessment, the observer's assessment and return to work. Finally, the information is combined into a simple method for scoring the overall outcome of surgery.
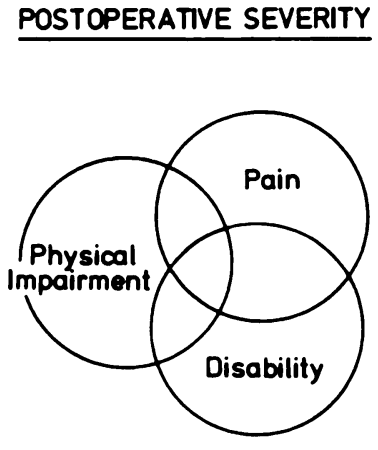

\section{ASSESSMENT OF OUTCOME}
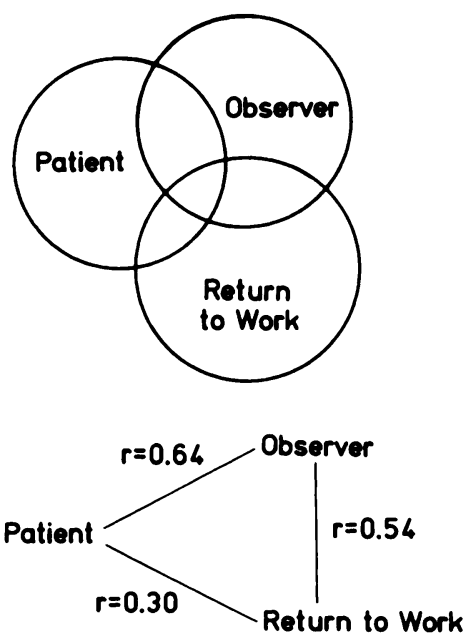

Fig. 1

The relationship between various measures of outcome $(r=$ correlation co-efficient). 
Table I. Details of patients, follow-up and results of assessments (see text)

\begin{tabular}{llllll}
\hline & Total & $\begin{array}{l}\text { Chemo- } \\
\text { nucleolysis }\end{array}$ & $\begin{array}{l}\text { Disc } \\
\text { operation }\end{array}$ & $\begin{array}{l}\text { Spinal } \\
\text { fusion }\end{array}$ & $\begin{array}{l}\text { Repeat } \\
\text { surgery }\end{array}$ \\
\hline $\begin{array}{l}\text { Number of patients } \\
\text { followed up }\end{array}$ & 185 & 49 & 91 & 20 & 25 \\
$\begin{array}{l}\text { Duration of follow-up } \\
\text { (months) }\end{array}$ & $26 \pm 12$ & $28 \pm 10$ & $19 \pm 7$ & $35 \pm 11$ & $40 \pm 11$ \\
\hline & Percentage of group & & & \\
\cline { 2 - 6 } & 81 & 77 & 90 & 60 & 72 \\
$\begin{array}{l}\text { Patient's assessment } \\
\text { as worthwhile }\end{array}$ & 59 & 61 & 68 & 32 & 40 \\
$\begin{array}{l}\text { Observer's assessment } \\
\text { good } \\
\text { fair } \\
\text { poor }\end{array}$ & 15 & 12 & 15 & 16 & 16 \\
$\begin{array}{l}\text { Returned to original } \\
\text { work }\end{array}$ & 63 & 80 & 64 & 42 & 39 \\
$\begin{array}{l}\text { Returned to modified } \\
\text { work }\end{array}$ & 8 & 6 & 7 & 21 & 9 \\
\hline
\end{tabular}

* Mean \pm standard deviation

Table II. The main influences on the three assessments of outcome. These were identified from a series of stepwise logistic regression analyses in which these factors were consistently significant $(p<0.05$ at each step of each regression).

\begin{tabular}{ll}
\hline Assessment & Influenced mainly by \\
\hline Patient & $\begin{array}{l}\text { Postoperative physical impairment } \\
\text { Type of surgery } \\
\text { Proportional improvement in disability }\end{array}$ \\
Observer & $\begin{array}{l}\text { Postoperative physical impairment } \\
\text { Postoperative pain }\end{array}$ \\
& $\begin{array}{l}\text { Postoperative disability } \\
\text { Return to work }\end{array}$ \\
& Postoperative disability \\
& Type of work \\
\hline
\end{tabular}

The relationship between measures of outcome. The results of each form of surgery were comparable to those in other published series; they illustrate some of the discrepancies which can occur between different methods of assessment (Table I). Overall, the patient's assessment was more favourable than either the observer's assessment or return to work. There were additional discrepancies between the different surgical groups. Comparing disc surgery and chemonucleolysis for the same condition, there was greater patient satisfaction in the disc surgery group, but a higher rate of return to work in the chemonucleolysis group. The relationship between the patient's assessment, the observer's assessment and return to work was measured by correlation co-efficients where 0 means the assessments are completely unrelated,
1 is complete agreement and 0.3 is approximately $10 \%$ overlap or variance in common. The results show that although the three measures of outcome were related to each other, this was certainly not an absolute relationship: although the assessments were obviously looking at the same outcome they were looking at different aspects of that outcome (Fig. 1).

On which point in time are assessments based? To determine whether the outcome was judged on the change resulting from surgery or simply on the end result, the three main assessments of outcome were each compared with both the pre-operative and postoperative state, both as actual values measured and as the change between them. If, however, a pre-operative measure is very high then, although it can fall as a result of surgery, it cannot possibly rise very much. The converse is true of a very low measure. Such "ceiling effects" can statistically bias the results; to exclude this the analysis made further allowance for proportional change.

A consistent finding in every analysis was that both the patient and the observer appeared to base their assessment mainly on the final postoperative state at the time of follow-up and were very little influenced by the pre-operative state or by the actual change produced by the operation (Table II). The likelihood that the patient would return to work was again almost entirely dependent on postoperative state. In certain situations, the change and proportional change had a lesser additional effect. The initial pre-operative severity had very little influence on the final outcome. In order to check these findings the analysis was repeated for each of the individual measurements carried out at each examination, but again the final postoperative findings had by far the greatest influence.

Which factors affect each assessment? Having shown that the postoperative state was the major influence, further analysis considered which particular postoperative factors influenced the patient's and observer's judgement of outcome and return to work (Table II). The observer's assessment was most influenced by the three clinical measures of severity: pain, disability, and physical impairment. The sex of the patient, demographic characteristics, psychological measures and behavioural symptoms and signs did not significantly influence the observer's assessment. On double-checking the previous analysis using these specific items, absolute change or proportional change resulting from surgery again had little effect on the observer's final assessment of the success or failure of surgery.

This analysis was repeated for the patient's own assessment. This appeared to depend mainly on: the postoperative physical impairment, the type of surgery performed and the proportional change in disability. The patient's sex and demographic characteristics again had no influence. Somewhat surprisingly, the degree of psychological distress and illness behaviour did not affect the patient's assessment. Most surprising of all, 
patients' own assessment of their pain on a pain scale did not appear to influence their assessment of the success or failure of surgery, at least when it was considered as an isolated variable.

Return to work again appeared to depend on the postoperative state. The most important influences which could be identified were postoperative disability and the nature of the patient's occupation. The analysis of return to work, however, was less clear than the other analyses and very few factors influencing return to work could be identified. Indeed, throughout the study it became increasingly obvious that social factors and work related factors were the most powerful influence on return to work, but, because of the initial study design, only limited social information was available.

Thus the patient's and observer's assessment and return to work were each based on different aspects of the low back disorder. They were all based mainly on postoperative severity but they were influenced to quite varying degrees by different measures of that severity; this explains the discrepancy between them.

Table III. The accuracy of assessing the outcome of discectomy, fusion or repeat surgery, using a simple arithmetical formula based on postoperative pain and physical impairment (see text)

\begin{tabular}{|c|c|c|c|}
\hline \multirow[b]{2}{*}{ Simple score } & \multicolumn{2}{|c|}{$\begin{array}{l}\text { Comprehensive assessment } \\
\text { by patient and observer }\end{array}$} & \multirow{2}{*}{$\begin{array}{l}\text { Accuracy of } \\
\text { simple score } \\
\text { (per cent) }\end{array}$} \\
\hline & Success & Failure & \\
\hline Success & 91 & 3 & 97 \\
\hline Failure & 4 & 30 & 88 \\
\hline
\end{tabular}

A simple method of rating outcome. In order to obtain an overall consensus of the success or failure of surgery it was necessary to develop a method of combining the patient's and observer's assessments. Return to work was excluded as it was influenced by too many extraneous and social factors. It was decided on the basis of logic and principle that for an operation to be considered successful, both the individual patient and the independent observer should rate the outcome as at least moderately successful, that is, "doubtful" or "fair". If either the patient or the observer considered that the surgery had not been worthwhile or had been a failure then the final rating should be considered as failure. If both patient and observer were doubtful then the outcome could hardly be considered an unqualified success. In order to combine the two judgements statistically each was scored $0,1,2$ : in the patient's assessment 0 - not worthwhile, 1 - doubtful, and 2 worthwhile; in the observer's assessment 0 - poor, 1 fair, and 2 -good. These two scores were then added to give an overall score from 0 to four. A combined score of three or more was taken to be a successful outcome, two or less a failure. This final, overall rating was then analysed in the same way as the previous individual assessments. As a cross-check, an alternative analysis was performed including an intermediate group of partial success, but gave almost identical results and did not add any useful or practical information.

Postoperative pain score and physical impairment were the strongest influences on the combined rating outcome. Based upon the statistical analysis, a simple arithmetical formula was developed which could accurately predict surgical success or failure on the combined rating.

Postoperative outcome $=1 / 4 \times$ physical impairment + $3 / 4 \times$ pain percentage -8

If the formula gave a positive result - outcome is graded failure.

If the formula gave a negative result - outcome is graded success.

This simple formula for success or failure of surgery agreed well with the total clinical assessment in nearly every case (Table III). It also gave similar results to the other measures of outcome in each separate surgical group.

\section{DISCUSSION}

There is no doubt that the results of low back surgery need to be improved, but an understanding of the factors which influence the assessment of outcome is fundamental to measuring future progress. Any operation performed primarily for the relief of pain is hampered by the lack of objective measures of success or failure. Although it is sometimes argued that only the patient can assess pain relief, this is an over-simplification; in our study the patient's own assessment of surgical outcome was surprisingly uninfluenced by severity of pain, at least as measured on a simple pain scale. Subjective assessments by the patient and the surgeon are clearly influenced by several aspects of clinical severity.

Our analysis has shown that all assessments of outcome appear to be based mainly on the final postoperative state rather than on any change produced by surgery. This may initially appear to be illogical, but it fits human pre-occupation with present problems and reflects inaccurate long-term memory of the preoperative state.

Patient and observer assessments were shown to be based to quite varying degrees on different measures of postoperative severity, thus explaining some of the discrepancies noted in previous studies. Despite the original criteria laid down for grading outcome as good, fair or poor, neither patient nor surgeon was influenced to any extent by whether or not surgery resulted in return to work. Conversely, return to work was determined to a surprisingly small extent by either the physical findings or the effect of surgery and was much more strongly influenced by social and work-related factors. This supports clinical experience and explains why the proportion of patients returning to work varies so much 
in reported series from different centres with different patient populations. Return to work by itself is a poor measure of outcome.

In order to obtain an overall assessment of outcome many of the factors influencing patient and surgeon need to be considered: this can then be reproduced surprisingly accurately by a simple arithmetical formula. Our present series of patients used to develop this formula were rigorously assessed; the method is unlikely to be quite so accurate when applied to other groups. Nevertheless the formula can be used by the surgeon to reproduce the combined assessment of the patient's own report and that of an independent observer. Such a scoring system may permit better comparison of surgical results in different series.
Our analysis has considered the assessment of outcome of surgery for the low back but some of the findings may apply also to assessment of other types of orthopaedic surgery, especially operations carried out primarily for the relief of pain. There is increasing demand for surgical audit, but this must be based upon an improved understanding of how surgical outcome should be assessed.

This study was supported by research grants from the Medical Research Council and the Back Pain Association. We would like to thank all the Glasgow orthopaedic surgeons who allowed us to study their patients.

No benefits in any form have been received or will be received from a commercial party related directly or indirectly to the subject of this article.

\section{REFERENCES}

Howe J, Frymoyer JW. The effects of questionnaire design on the determination of end results in lumbar spinal surgery. Spine $1985 ; 10: 804-5$.

Main CJ. The modified somatic perception questionnaire (MSPQ). J Psychosom Res 1983;27:503-14.

Ransford AO, Cairns D, Mooney V. The pain drawing as an to the psychological evaluation of patients with low-back pain. Spine $1976 ; 1: 127-34$.

Reilly S. Judgement of outcome of spinal surgery. BSc Thesis Dept of Statistics, University of Glasgow: 1987.

Spangfort EV. The lumbar disc herniation: a computer-aided analysis of 2,504 operations. Acta Orthop Scand [Suppl] 1972: Suppl 142.

Waddell G. Clinical assessment of lumbar impairment. Clin Orthop 1987;221:110-20.
Waddell G, Main CJ. Assessment of severity of low-back disorders. Spine 1984;9:204-8.

Waddell G, Morris EW, Di Paola MP, Bircher M, Finlayson D. A concept of illness tested as an improved basis for surgical decisions in low-back disorders. Spine 1986;11:712-9.

Waddell G, Main CJ, Morris EW, Di Paola M, Gray ICM. Chronic low-back pain, psychologic distress, and illness behaviour. Spine 1984;9:209-13.

Waddell G, McCulloch JA, Kummel E, Venner RM. Nonorganic physical signs in low-back pain. Spine 1980;5:117-25.

Weinstein J, Spratt KF, Lehmann T, McNeill T, Hejna W. Lumbar disc herniation: a comparison of results of chemonucleolysis and open discectomy after ten years. J Bone Joint Surg [Am] $1986 ; 68-A: 43-54$.

Zung WWK. A self-rating depression scale. Arch Gen Psychiatry $1965 ; 12: 63-70$. 